\title{
Influence of Mud Content in Sand and Gravel on Water Reducer in Concrete
}

\author{
Qiheng Wang
}

Undergraduate Department, Anhui Technical College of Water Resources and Hydroelectric Power, Hefei 231603, China

Corresponding Author Email: wangqiheng@ahsdxy.edu.cn

https://doi.org/10.18280/acsm.430402

Received: 28 April 2019

Accepted: 1 July 2019

\section{Keywords:}

mud content, water reducer, concrete, compressive strength, porosity

\begin{abstract}
The mud content in sand and gravel suppresses the fluidity and water reducer effect of concrete. To disclose the impacts of mud content on water reducer, this paper explores the microscale interaction between three kinds of mud (i.e. montmorillonite, kaolin and illite) and one water reducer (i.e. polycarboxylate superplasticizer), and tests the compressive strength and porosity of cement mortar with each type of mud. In addition, an anti-mud agent was prepared to enhance the dispersion effect of the water reducer. The results show that the compressive strength of hardened cement mortar is negatively correlated with mud content. The equilibrium zeta potential of two types of mud is higher than that of cement particles. The optimal reaction conditions for the anti-mud agent are weak alkalinity, reaction temperature of $70{ }^{\circ} \mathrm{C}$, initiator dosage of $6 \%$, and reaction time of $5 \mathrm{~h}$. The research findings provide new insights into the development and application of water reducer with anti-mud agent.
\end{abstract}

\section{INTRODUCTION}

Sand and gravel form the "skeleton" of concrete. The two materials directly affect many mechanical parameters of concrete, such as compressive strength and the elasticity modulus $[1,2]$. However, the sand and gravel resources in China are quickly depleting. As a result, the quality of sand and gravel used in concrete is often not up to standard. For example, the mud content ( $>20 \%)$ of unwashed sand and gravel severely exceeds the limit, due to the high bulk porosity $(>45 \%)$ of the two materials [3]. The high mud content has a negative impact on concrete performance [4]. In fact, mud inclusion is one of the top three threats to concrete performance, alongside with syneresis cracking and bleeding [5]. This threat can be solved by the addition of water reducer, a popular additive to the concrete.

Water reducer can enhance the mechanical properties and extend the service life of concrete [6-8]. The application range of water reducer is rapidly expanding. Many water reducers have been developed and applied to concrete. Their impacts on the mechanics and microstructures of concrete have also been explored. However, there is no report on the bonding properties of water reducers and other components of concrete, namely, sand, gravel and mud $[9,10]$.

The mud removal effect of water reducer depends on the adsorption competition of mud powder and cement. After being added to the concrete, the water reducer is absorbed on the surface of mud powder with anionic groups. In many cases, the mud power outperforms the cement in the adsorption capacity and adsorption rate of water reducer [11]. Therefore, it is very meaningful to study the effects of the mud in sand and gravel on the performance of water-reducing agent. Understanding the effects helps to improve the mechanical strength and durability of concrete [12].

This paper probes into the effects of mud content in sand and gravel on water reducer in concrete, and models the microscale interaction between mud powder and water reducer.

\section{MATERIALS AND METHODS}

\subsection{Test materials}

According to the X-ray fluorescence (XRF) results (Table 1), the main test materials include three kinds of mud (i.e. montmorillonite, kaolin and illite) and one water reducer (i.e. polycarboxylate superplasticizer). The three kinds of mud were mixed with sand and added to the concrete. The mud content of concrete samples was controlled between $1 \%$ and $10 \%$ (mass percent). Tables 2 and 3 list the mix ratios of cement mortar and concrete for the test, respectively.

Table 1. Test materials

\begin{tabular}{cccccccccc}
\hline \multirow{2}{*}{ Material } & Mean particle size & \multicolumn{10}{c}{ Mass fraction (wt\%) } \\
\cline { 2 - 10 } & & $\mathrm{SiO}_{2}$ & $\mathrm{Al}_{2} \mathrm{O}_{3}$ & $\mathrm{CaO}$ & $\mathrm{MgO}$ & $\mathrm{Fe}_{2} \mathrm{O}_{3}$ & $\mathrm{Na}_{2} \mathrm{O}$ & $\mathrm{K}_{2} \mathrm{O}$ & LOI \\
\hline Cement & 10.68 & 24.03 & 5.12 & 61.96 & 2.08 & 2.56 & 0.04 & 0.82 & 3.39 \\
Montmorillonite & 5.60 & 68.80 & 17.86 & 1.07 & 4.46 & 3.33 & 2.84 & 0.87 & 0.77 \\
Kaolin & 4.98 & 52.40 & 39.6 & 0.3 & 2.57 & 0.29 & 1.74 & 0.69 & 2.41 \\
Illite & 6.89 & 52.20 & 40.6 & 0.82 & 2.04 & 1.30 & 1.27 & 0.65 & 1.12 \\
\hline
\end{tabular}


Table 2. Mix ratio of cement mortar

\begin{tabular}{cccc}
\hline Standard sand $(\mathrm{g})$ & Cement $(\mathrm{g})$ & Water $(\mathrm{g})$ & Water reducer $(\mathrm{g})$ \\
\hline 1,350 & 450 & 225 & 1.0 \\
\hline
\end{tabular}

Table 3. Mix ratio of test concrete

\begin{tabular}{ccccccc}
\hline Cement $(\mathrm{g})$ & Limestone powder $(\mathrm{g})$ & Sand $(\mathrm{g})$ & Gravel $(\mathrm{g})$ & Fly ash $(\mathrm{g})$ & Water reducer $(\mathrm{g})$ & Water $(\mathrm{g})$ \\
\hline 260 & 80 & 880 & 975 & 100 & $0.3 \%$ & 200 \\
\hline
\end{tabular}

\subsection{Test methods}

The mechanical strength of hardened cement mortar was tested according to the Standard for Test Method of Mechanical Properties on Ordinary Concrete (GB/T 500812002). Three concrete samples (size: $150 \mathrm{~mm} * 150 \mathrm{~mm} * 150 \mathrm{~mm})$ were prepared with each type of mud. The mean value of the three samples was obtained as the final value for the concrete with the corresponding type of mud. To characterize the apparent morphology of mud and cement, mud powders and cement particles were attached to the conducting resin, and their zeta potentials were measured by an electrophoresis apparatus. In addition, the viscosity of the cement mortar with different contents of each type of mud was tested every $15 \mathrm{~min}$ using an NDJ-5S digital rotational viscometer.

\section{RESULTS AND DISCUSSION}

\subsection{Relationship between mud content and compressive strength}

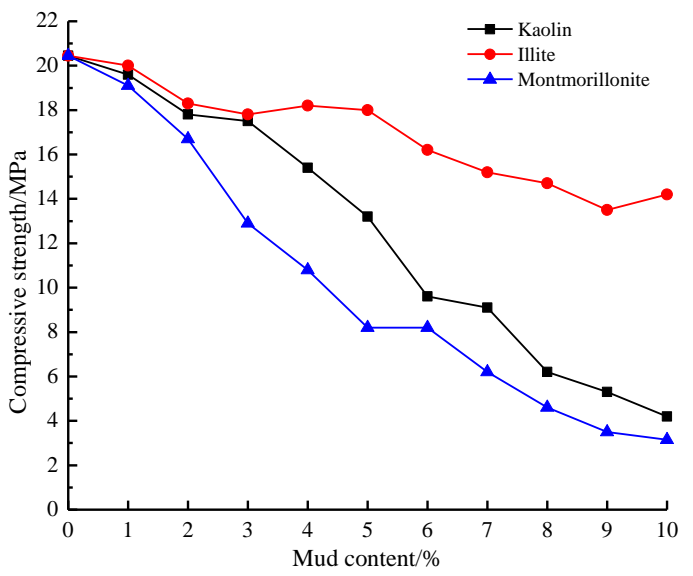

(a) $3 \mathrm{~d}$
It is generally agreed that mud reduces the fluidity of concrete. The previous research [13] has found that the concrete with $3 \%$ mud has a weak fluidity, which still meets construction requirements; the concrete with $>5 \%$ mud suffers a huge loss in 60min flow expansion; the concrete with $>8 \%$ mud faces a sharp decline in mechanical performance.

Figure 1 shows the compressive strength-mud content curve of hardened cement mortar with each type of mud. The compressive strengths were measured on $3 \mathrm{~d}, 7 \mathrm{~d}$ and $28 \mathrm{~d}$, respectively. It can be seen that the compressive strength of hardened cement mortar always decreased with the growth in mud content. The hardened cement mortar containing montmorillonite witnessed the fastest decline in compressive strength, followed by that containing kaolin and that containing illite. The compressive strength of hardened cement mortar plunged deeply, when the kaolin content reached $5 \sim 6 \%$. This means the accumulation of kaolin greatly weakens the mechanical properties of hardened cement mortar. For the hardened cement mortar added with illite, the compressive strength decreased less significantly than that added with kaolin: the $28 \mathrm{~d}$ compressive strength dropped by less than $20 \%$ at the illite content of $10 \%$.

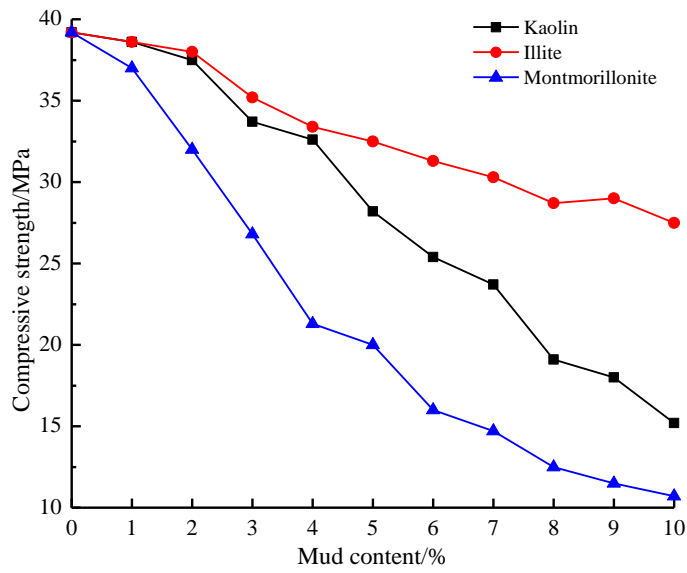

(b) $7 \mathrm{~d}$

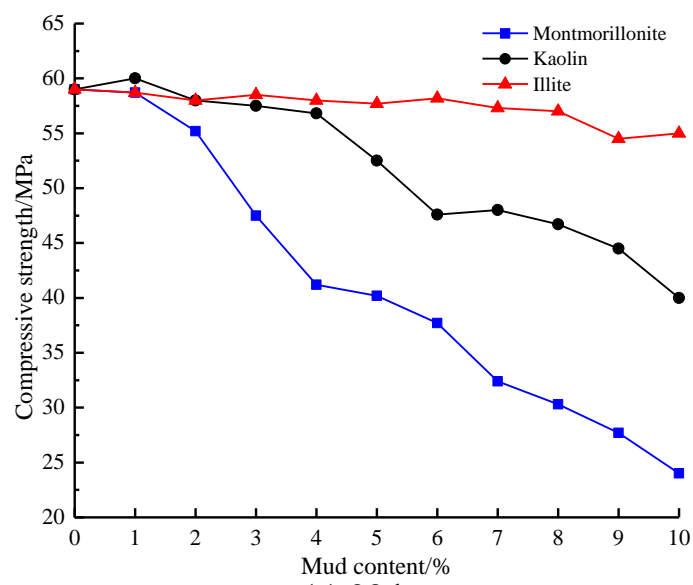

(c) $28 \mathrm{~d}$

Figure 1. Compressive strength-mud content curves 


\subsection{Relationship between zeta potential and water reducer concentration}

The dispersion resistance of concrete is greatly affected by the zeta potential of cement particles in the polycarboxylate superplasticizer solution. In general, a large zeta potential indicates a good dispersibility of the polycarboxylate superplasticizer.

Figure 2 presents the zeta potential-water reducer concentration curves of cement, kaolin and montmorillonite. The zeta potentials were measured on the surface of cement and mud particles. With the growing concentration of polycarboxylate superplasticizer, the zeta potential on the surface of cement particles continuously decreased before reaching the equilibrium. For the two types of mud, the zeta potential changed in a similar trend as cement, but reached higher levels at the equilibrium state. Thus, the mud powders have a higher absorbability for polycarboxylate superplasticizer than cement particles.

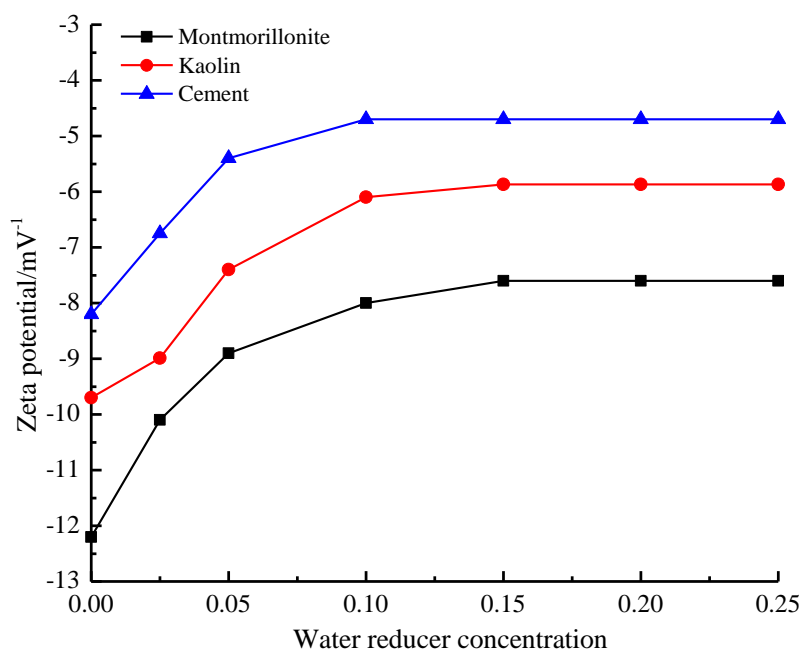

Figure 2. Zeta potential-water reducer concentration curves

\subsection{Relationship between zeta potential and retention time}

The dispersion resistance of concrete also depends on the retention time of cement particles in the polycarboxylate superplasticizer solution.

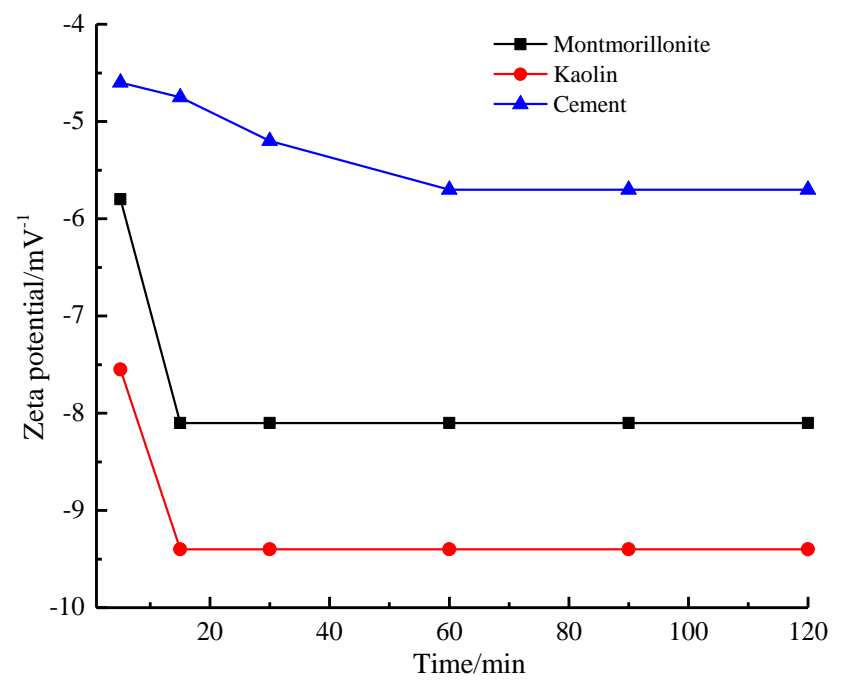

Figure 3. Zeta potential-retention time curves
Figure 3 gives the zeta potential-retention time curves of cement, kaolin and montmorillonite. The zeta potentials were also measured on the surface of cement and mud particles. The zeta potentials of cement and mud particles all increased with the elapse of time. By equilibrium potential, the materials can be ranked as montmorillonite $<$ kaolin $<$ cement. In addition, the two types of muds reached the equilibrium potentials faster than cement.

\subsection{Relationship between viscosity and retention time}

Figure 4 displays the viscosity-retention time curves of pure cement mortar, the cement mortar with $3 \%$ montmorillonite, and the cement mortar with $3 \%$ kaolin. The viscosity of all the three materials firstly decreased and then increased over the time. At the same time point, the three materials can be ranked as cement mortar, the cement mortar with $3 \%$ kaolin and the cement mortar with $3 \%$ montmorillonite, in descending order of viscosity.

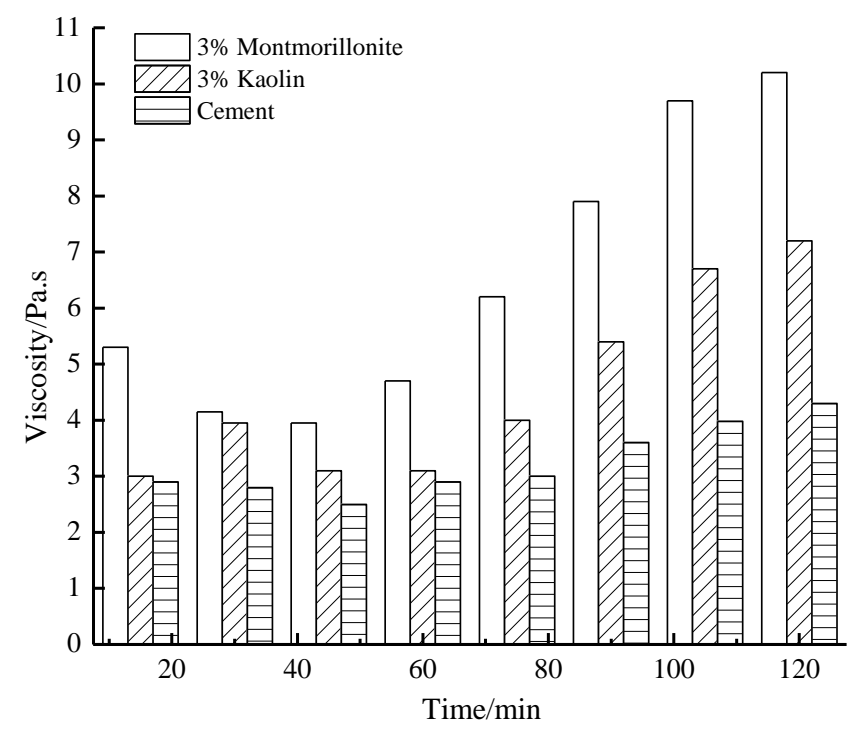

Figure 4. Viscosity-retention time curves

\subsection{Effects of reaction conditions on anti-mud agent}

All types of mud weaken the working performance of polycarboxylate superplasticizer, but to varied degrees. To mitigate the weakening effect, a mud-resistant polymer was added to the concrete, forming a synthetic anti-mud agent with polycarboxylate superplasticizer. The effectiveness of the anti-mud agent may be influenced by reaction temperature, initiator dosage, reaction time and $\mathrm{pH}$.

Table 4. Influence of reaction temperature on anti-mud agent

\begin{tabular}{ccc}
\hline Reaction temperature $/{ }^{\circ} \mathrm{C}$ & \multicolumn{2}{c}{ Flow time through marsh cone/s } \\
\cline { 2 - 3 } & Mixing 5min & Mixing 60min \\
\hline 60 & 7.56 & - \\
65 & 5.23 & 15.23 \\
70 & 3.91 & 10.58 \\
75 & 4.52 & 12.00 \\
80 & 4.64 & 13.32 \\
\hline
\end{tabular}

Table 4 sums up the influence of reaction temperature on the performance of the anti-mud agent. According to the data in the table, the mud-containing cement mortar flowed through 
the marsh cone in the shortest time under $70{ }^{\circ} \mathrm{C}$. This means the synthetic anti-mud agent has the best dispersion effect at $70{ }^{\circ} \mathrm{C}$.

Figure 5 shows the influence of initiator dosage on the performance of the anti-mud agent. With the increase of initiator dosage, the flow time of mud-containing cement mortar decreased first and then increased, and minimized at the initiator dosage of $6 \%$. Therefore, the mud-containing cement mortar has the best fluidity at the initiator dosage of $6 \%$, making this dosage the optimal level for the anti-mud agent.

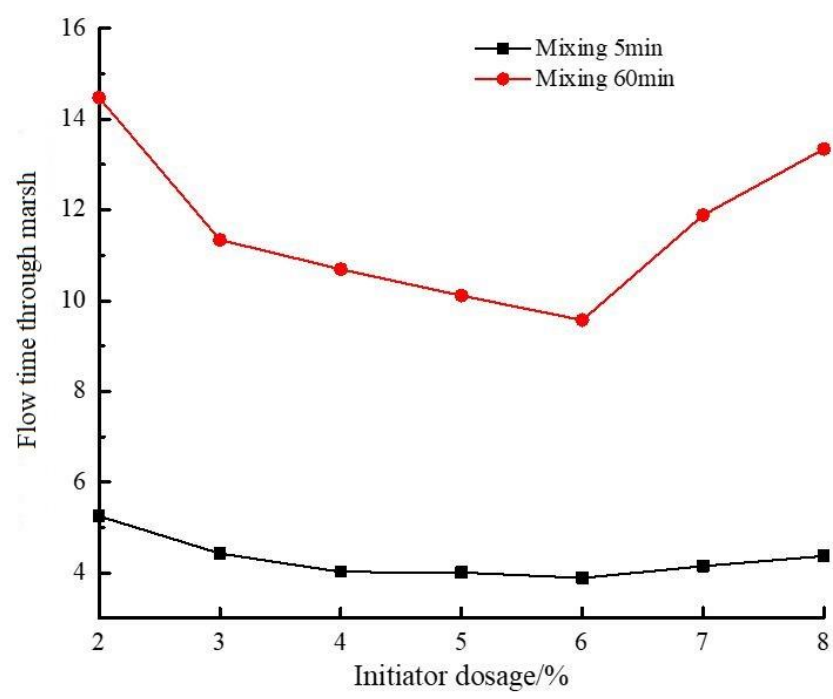

Figure 5. The relationship between flow time through marsh cone and initiator dosage

Figure 6 displays the influence of reaction time on the performance of the anti-mud agent. The mud-containing cement mortar achieved the best fluidity when the reaction proceeded for $5 \mathrm{~h}$. Further growth in reaction time suppressed the fluidity of the mortar. This is because an excessively long reaction will increase the molecular weight of the anti-mud polymer, expanding the volume of the anti-mud agent.

Table 5 describes the influence of $\mathrm{pH}$ on the performance of the anti-mud agent. As shown in the table, as the $\mathrm{pH}$ increased, the mud-containing mortar took a longer time to flow through the marsh cone, reflecting a decline in mortar fluidity. This means the mud resistance weakens in an acidic environment.
Therefore, the anti-mud agent should be synthetized in a weak alkaline environment.

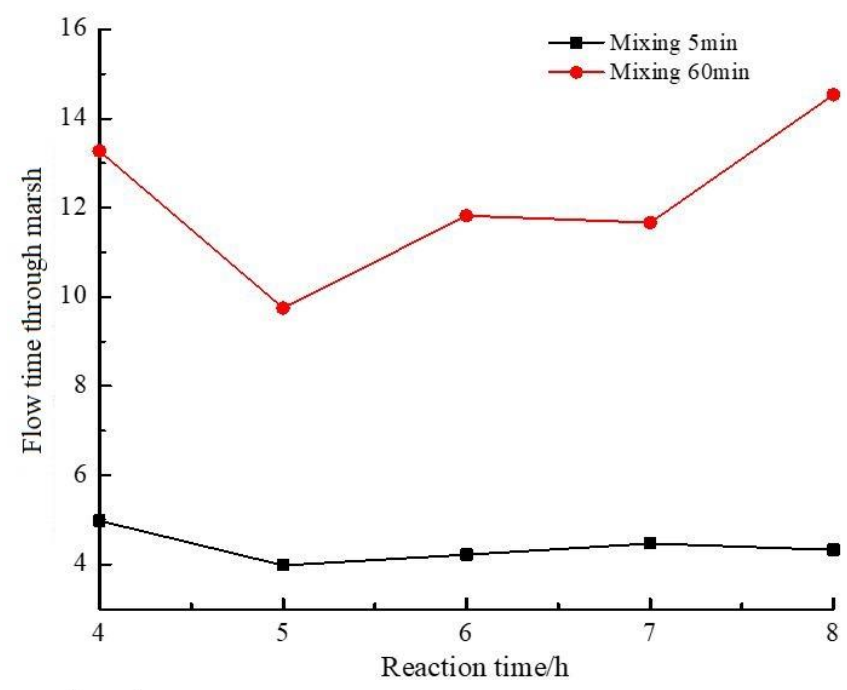

Figure 6. The relationship between flow time through marsh cone and reaction time.

Table 5. The relationship between flow time through marsh cone and $\mathrm{pH}$

\begin{tabular}{ccc}
\hline $\mathrm{pH}$ & \multicolumn{2}{c}{ Flow time through marsh cone/s } \\
\cline { 2 - 3 } & Mixing 5min & Mixing 60min \\
\hline 4 & 7.88 & - \\
5 & 7.12 & - \\
6 & 5.46 & 18.72 \\
7 & 3.91 & 9.94 \\
8 & 3.94 & 9.87 \\
9 & 3.90 & 9.64 \\
\hline
\end{tabular}

\subsection{Effects of anti-mud agent on hardened cement mortar}

The anti-mud agent could change the late-stage performance of cement mortar, including compressive strength and porosity. In this paper, the compressive strength and porosity of cement mortar with each type of mud are measured before and after using the anti-mud agent. The mix ratios of the cement mortars are listed in Table 6 . The measured results are recorded in Tables 7 and 8 .

Table 6. Mix ratio of cement mortar with each type of mud

\begin{tabular}{ccccccc}
\hline Group code & \multicolumn{6}{c}{ Dosage of cement mortar/g } \\
\cline { 2 - 7 } & Sand & Cement & Mud & Water & Water reducer & Anti-mud agent \\
\hline A & 1,350 & 450 & 0 & 225 & 1.0 & 0 \\
B & 1,350 & 450 & 75 & 225 & 1.0 & 0 \\
C & 1,350 & 450 & 75 & 225 & 1.0 & 0.5 \\
\hline
\end{tabular}

Note: Group A is the samples containing montmorillonite; Group B is the samples containing kaolin; Group C is the samples containing illite.

As shown in Figure 7, the three sample groups can be ranked as Sample B > Sample C > Sample A by the original porosity; after the anti-mud agent was added, all sample groups saw a significant decline in porosity, but stayed ahead of pure cement mortar in terms of $28 \mathrm{~d}$ porosity. As shown in Figure 8, all samples had greater compressive strength than pure cement mortar on $3 \mathrm{~d}$. Moreover, the three sample groups can be ranked as Sample A $>$ Sample C > Sample B by 28d compressive strength.

Table 7. Measured porosity curing age

\begin{tabular}{cccc}
\hline & \multicolumn{3}{c}{ Porosity $/ \%$} \\
\cline { 2 - 4 } & A & B & C \\
\hline $7 \mathrm{~d}$ & 17.45 & 42.42 & 25.58 \\
$28 \mathrm{~d}$ & 13.71 & 30.74 & 20.04 \\
\hline
\end{tabular}


Table 8. Measured compressive strength

\begin{tabular}{cccc}
\hline Curing age & \multicolumn{3}{c}{ Compressive strength/MPa } \\
\cline { 2 - 4 } & $\mathrm{A}$ & $\mathrm{B}$ & $\mathrm{C}$ \\
\hline $3 \mathrm{~d}$ & 20.36 & 8.32 & 30.77 \\
$28 \mathrm{~d}$ & 59.11 & 40.39 & 51.51 \\
\hline
\end{tabular}

\section{CONCLUSIONS}

This paper studies the impacts of mud content in sand and gravel on water reducer in concrete, and explores the microscopic mechanism between mud powder and water reducer. The main conclusions are as follows:

(1) The compressive strength of hardened cement mortar always decreased with the growth in mud content. The hardened cement mortar containing montmorillonite witnessed the fastest decline in compressive strength, followed by that containing kaolin and that containing illite.

(2) With the growing concentration of polycarboxylate superplasticizer, the zeta potential on the surface of cement particles continuously decreased before reaching the equilibrium. For the two types of mud, the zeta potential changed in a similar trend as cement, but reached higher levels at the equilibrium state.

(3) The effectiveness of the anti-mud agent may be influenced by reaction temperature, initiator dosage, reaction time and $\mathrm{pH}$. To maximize the dispersion effect, the anti-mud agent should be synthesized under a weak alkaline environment at the reaction temperature of $70^{\circ} \mathrm{C}$, the initiator dosage of $6 \%$, and the reaction time of $5 \mathrm{~h}$.

\section{REFERENCES}

[1] Menhosh, A.A., Wang, Y., Wang, Y., Augusthus-Nelson, L. (2018). Long term durability properties of concrete modified with metakaolin and polymer admixture. Construction \& Building Materials, 172: 41-51. https://doi.org/10.1016/j.conbuildmat.2018.03.215

[2] Khay, S.E.E., Neji, J., Loulizi, A. (2010). Shrinkage properties of compacted sand concrete used in pavements. Construction \& Building Materials, 24(9): 1790-1795. https://doi.org/10.1016/j.conbuildmat.2010.02.008

[3] Xiao, J., Li, L., Tam, V.W.Y., Li, H. (2014). The state of the art regarding the long-term properties of recycled aggregate concrete. Structural Concrete, 15(1): 3-12. https://doi.org/10.1002/suco.201300024

[4] Tahar, Z.E.A., Ngo, T.T., Kadri, E.H., Bouvet, A.,
Debieb, F., Aggoun, S. (2017). Effect of cement and admixture on the utilization of recycled aggregates in concrete. Construction \& Building Materials, 149: 91102. https://doi.org/10.1016/j.conbuildmat.2017.04.152

[5] Ribeiro, P.R.E., Souza, V.S., Melo, A.C.G.R.D., Neto, A.T.M., Santos, R.C., Takahashi, J.A. (2018). Chemical composition, bioactivities and kinematic viscosity of cucurbita argyrosperma seed oil. Chemical Engineering Transactions, 64:

217-222. https://doi.org/10.3303/CET1864037

[6] Guo, Z., Feng, Q., Wang, W., Huang, Y., Deng, J., Xu, Z. (2016). Study on flotation tailings of kaolinite-type pyrite when used as cement admixture and concrete admixture. Procedia Environmental Sciences, 31: 644652. https://doi.org/10.1016/j.proenv.2016.02.118

[7] Yoo, S.W., Kwon, S.J., Sang, H.J. (2012). Analysis technique for autogenous shrinkage in high performance concrete with mineral and chemical admixtures. Construction \& Building Materials, 34(3): 1-10. https://doi.org/10.1016/j.conbuildmat.2012.02.005

[8] Hu, M., Liu, Y.X., Ren, J.B., Zhang, Y., Song, L.B. (2017). Temperature-induced slaking characteristics of mudstone during dry-wet cycles. International Journal of Heat and Technology, 35(2): 339-346. https://doi.org/10.18280/ijht.350215

[9] Wang, Y., Yan, Y. (2015). Study on performances of the concrete pavement from zincilate. Proceedings of the 11th International Congress for Applied Mineralogy, pp. 365-371. https://doi.org/10.1007/978-3-319-13948-7 37

[10] Nie, Q., Zhou, C., Shu, X., He, Q., Huang, B. (2014). Chemical, mechanical, and durability properties of concrete with local mineral admixtures under sulfate environment in northwest China. Materials, 7(5): 37723785.

[11] Tahar, Z.E.A., Kadri, E.H., Ngo, T.T., Bouvet, A., Kaci, A. (2016). Influence of recycled sand and gravel on the rheological and mechanical characteristic of concrete. Journal of Adhesion Science \& Technology, 30(4): 392411. https://doi.org/10.1080/01694243.2015.1101185

[12] Saxena, S., Pofale, A.D. (2017). Effective utilization of fly ash and waste gravel in green concrete by replacing natural sand and crushed coarse aggregate. Materials Today Proceedings, 4(9): 9777-9783. https://doi.org/10.1016/j.matpr.2017.06.266

[13] Ismail, A.I.M., Darwish, H. (2014). Engineering behaviour of waste glass as aggregates in concrete containing sand and gravels. Interceram International Ceramic Review, 63(1): 45-48. https://doi.org/10.1007/BF03401035 